\title{
Integration of Information Technology into Music Education to Cultivate Creative Thinking Among Middle School Students
}

\author{
Lanting Zhang* \\ College of Music, Guangxi Normal University, Guilin 541001, Guangxi Zhuang Autonomous Region, China \\ *Corresponding author: Lanting Zhang, 1642312224@qq.com
}

Copyright: () 2022 Author(s). This is an open-access article distributed under the terms of the Creative Commons Attribution License (CC BY 4.0), permitting distribution and reproduction in any medium, provided the original work is cited.

\begin{abstract}
Creative thinking is an important thinking skill for primary and secondary school students in the learning stage. In music education, through the integration of information technology into classroom teaching, a series of measures have been taken: (1) changing the way of music creation; (2) guiding students to participate in classroom practice; (3) exercising students' reverse thinking for analysis. The full use of information technology in music education promotes the improvement of students' imagination, provides more space for students to create, changes students' inherent way of thinking, enables students to look at problems from a multi-level and multi-angle perspective, as well as trains students to improvise. Teaching practice has proven that the development of creative thinking reflects the overall quality of students. The integration of information technology into music education is of great significance to cultivate creative thinking among middle school students.
\end{abstract}

Keywords: Information technology; Music education; Creative thinking

Online publication: January 20, 2022

\section{Introduction}

It has been clearly stated in the "Music Curriculum Standards for Compulsory Education (2011 Edition)" (hereinafter, referred to as the "new curriculum standard") that music is a very creative art. The purpose of music creation in primary and secondary school curriculum is to enrich students' imagination and develop their creative potential through music. In the teaching process, it is necessary to set vivid and interesting creative activity contents, forms, and situations, develop students' imagination, and enhance students' creative consciousness ${ }^{[1]}$. Creative thinking music activities, on the stage of compulsory education, are carried out to assist students master music knowledge and encourage their participation in music activities. The introduction of information technology into music education and its integration with the curriculum have effectively promoted the implementation of music activities in classrooms. For students, the use of information technology in middle schools can improve students' music literacy and cultivate students' innovative spirit. For teachers, integrating information technology into teaching activities can help create different learning situations for students at different stages and a good learning environment. On this basis, teachers can then impart the necessary basic knowledge of music and carry out various forms of creative practical activities. Therefore, in classroom teaching, teachers will not only stimulate students' interest in learning, but also cultivate their creative thinking by using information technology reasonably and effectively. 


\section{Essence of creative thinking}

Creative thinking is an advanced psychological activity of human beings. It is based on the ability to understand, perceive, memorize, and form associations. It is different from general thinking. Creative thinking is the re-creation of thinking and has the characteristics of thinking. Creative thinking reflects the essence and internal relationship of objective things, including divergent thinking, intuition, insight, and other components. It is a novel and unique thinking achievement based on original thinking. Creative thinking requires long-term knowledge accumulation, which involves the processing and reproduction of knowledge. Creativity is the core of creative thinking. The development of creativity is inseparable from thinking activities, such as association, imagination, and intuition.

\subsection{Characteristics of creative thinking}

Creative thinking is closely linked with creative activities. The development of creative thinking is often inseparable from creative activities. The results of creative thinking have social value and are derived from the ability of conception, association, and imagination. It has its own characteristics, which differs from others; it is novel, advanced, flexible, abrupt, unique, and non-repetitive ${ }^{[2]}$.

\subsection{Importance of cultivating creative thinking among middle school students}

The new curriculum standard pointed out that creation is a learning field that gives full play to students' imagination and thinking potential. It is a process and channel for students to practice music creation as well as explore their creative thinking skills. It is of great significance for cultivating innovative talents ${ }^{[3]}$. Creative thinking is an important thinking skill for middle school students in the learning stage. Teachers should cultivate students' divergent thinking, enrich their imagination, and reasonably carry out music teaching practice. They should also actively cultivate students' improvisation skills and encourage them to actively participate in music practice. Teachers should not only pay attention to students' learning process, but also allow students to explore music independently, so as to improve their cognitive level in regard to music. The process of learning is the process of accepting knowledge and creating knowledge. By constantly exploring new knowledge and changing the existing thinking, students' creative thinking can be better cultivated.

\section{Integration of information technology into music education}

The integration of information technology into music education drives teachers to a "student-centered" classroom environment. In this environment, it is very important to cultivate students' interest in learning. The use of information technology is not only another form of technology added in the classroom, but it makes information technology a meaningful teaching method. The integration of information technology into music education enriches teaching resources and teaching contents. Teachers can obtain teaching resources through a variety of ways to provide students with more novel learning contents. It gives students more opportunities to explore and stimulates their interest in learning.

\subsection{Renewal of the teaching mode}

The original way of teaching in music embraces the teaching mode of a one-way output from teachers to students, in which students accept the output passively. There is a lack of interaction between teachers and students in the classroom. The content is single, the classroom atmosphere is boring, and it does not stimulate students' interest in learning. In that case, the learning efficiency is poor, and the participation of students is low. Therefore, education is not only for students to memorize the knowledge taught by teachers, 
but rather, a meaningful interaction with students' own ideas. The integration of information technology into music teaching, including a variety of music software and PowerPoint courseware to display communication, gives full play to the initiative of students and encourages them to actively explore, learn, and share their own experiences. It does not only improve teachers' teaching efficiency, but also enhance students' innovative consciousness. It liberates students' nature and improves their music aesthetic ability as well as innovation skills.

\subsection{Sharing of teaching resources}

The teaching resources of music courses can be shared. Resources include course content, teaching characteristics, teaching resources, etc. For example, through the information platform, teachers can acquire higher quality teaching content and teaching resources to provide students with richer teaching content. By creating a digital music library, teachers can select the songs that students are interested in, classify and organize those songs, and then upload them to the music library in advance. In this way, students can learn independently through the digital music library, while teachers can timely gauge students' learning progress and their mastery of the songs through online clock-out. Through the information platform, teachers and students can communicate; in addition, teachers can help students solve practical problems in a timely manner. The information platform meets the learning needs of students and provides students with richer resources. Between teachers, they can establish a shared network hard disk to sort out and consolidate music knowledge. Excellent lesson plans, pictures, high-quality class videos, etc. can be shared on the network hard disk. Contents can be added to the network hard disk at any time, so as to achieve resource sharing among teachers. In that way, teachers would be able to provide richer teaching contents and higher quality teaching resources to their students.

\subsection{Grasping the new pattern of "one body with two wings"}

In music education, the new pattern of "one body with two wings" should be grasped. Aesthetic perception, artistic expression, and cultural understanding are integrated into the two-way monitoring of "what to teach" and "to what extent to teach" among teachers as well as "what to learn" and "to what level to learn" among students. This forms a three-dimensional framework of cross-interaction, which ensures the improvement of the quality of teaching and learning. The integration of information technology into classroom teaching has changed the traditional teaching methods and created a more efficient learning through mutual cooperation and exploration among students. Teachers need to really consider the students, fully understand their learning needs, and encourage them to participate in music activities. With the help of information technology, teachers can enrich the teaching methods in music as well as realize the effective connection between teaching and learning.

\section{Strategies of using information technology to cultivate creative thinking}

Creative thinking is gradually formed in the process of exploring new knowledge and learning new skills. Therefore, in classroom teaching, teachers should break through students' existing thinking and provide students with a creative space. It is necessary to make rational use of information technology to assist music teaching, improve the teaching quality, and give full play to the advantages of audio-visual combination, rich resources, and audio-visual integration of information technology.

\subsection{Changing the way of music creation and cultivating students' creativity}

The introduction of electronic music in music classes has changed the original performance and listening effect of music editing, recording, and performance. Contents created by students during classes can be 
presented on the spot. For example, Sibelius can be used for music editing; this software does not only replace pen and paper, but also realize multi-part writing and improve the editing efficiency. Students also can use MIDI keyboards for real-time recording to improve the accuracy of pitch and rhythm. One of the advantages of MIDI is that it can be used with a sequencer, which has rich storage and editing functions; thus, certain music elements, such as the strength and speed, can be controlled, and students' editing efficiency can be improved. With more sound sources in the classroom, students can appreciate various music styles from different cultures and understand multilingual cultures while carrying forward their national cultures; this would improve students' aesthetic ability. In classrooms, common video editing software, such as Video Studio, MediaEditor, and other software for music video on-site editing can be used. The use of Flash software in music courseware makes the courseware effect more innovative and exciting; In that way, it can better stimulate students' interest, enrich students' imagination, and improve their creative ability. In addition to embodying the principles of learning, information technology can be used by students to create and recreate musical performances.

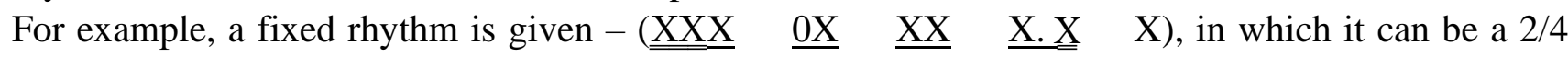
beat or 3/4 beat. Students are then required to create the rhythm on-site.

The rhythm created by the students is as follows:

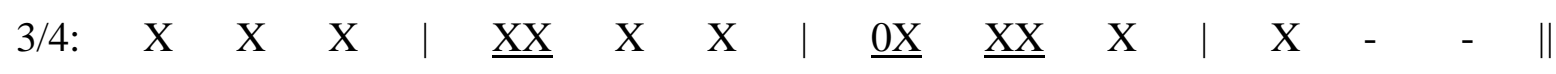

Adaptation: The rhythm of music that goes on

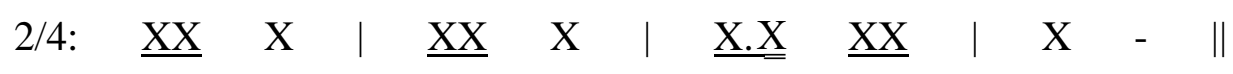

Through the compilation of rhythms, students have the opportunity to understand the law of $2 / 4$ and $3 / 4$ rhythms. The rhythm created by the students can then be adapted into the ongoing music, in which the sounds made by a small military drum can be added to help the students fully experience the characteristics of the ongoing music rhythm. By means of information technology, students can experience the changes of rhythm. In that way, they would be able to learn performance flexibility and improve their improvisation skills.

\subsection{Emphasizing on music appreciation and guiding students to participate in classroom practice}

Appreciation is the main way to improve students' cultural literacy, and learning to appreciate is the premise of cultivating creative thinking. In music appreciation class, students' music aesthetic cognition and evaluation ability can be well cultivated through listening to music as well as learning music history and culture knowledge. The process of music appreciation is a creative thinking process, and it involves information reprocessing. When appreciating various music works, students would have their own unique ideas. They can make good use of music elements, such as the melody, style, and emotion, to interpret the content of these music works based on their own ideas.

For example, when listening to "The Elephant" in the "Carnival of the Animals," teachers can play music through multimedia to let students listen to the changes in the melody. While listening, teachers can again use multimedia to play videos of elephants walking, so that students can relate to the emotions in "The Elephant." In this situation, students would begin to imagine and give full play to their own imaginations. Students can then draw melody lines and design maps through a variety of shapes, graphics, and colors while listening to the music; they can also divide phrases and analyze the emotions contained in the music.

The pictures drawn by the students are as shown in Figure 1. 

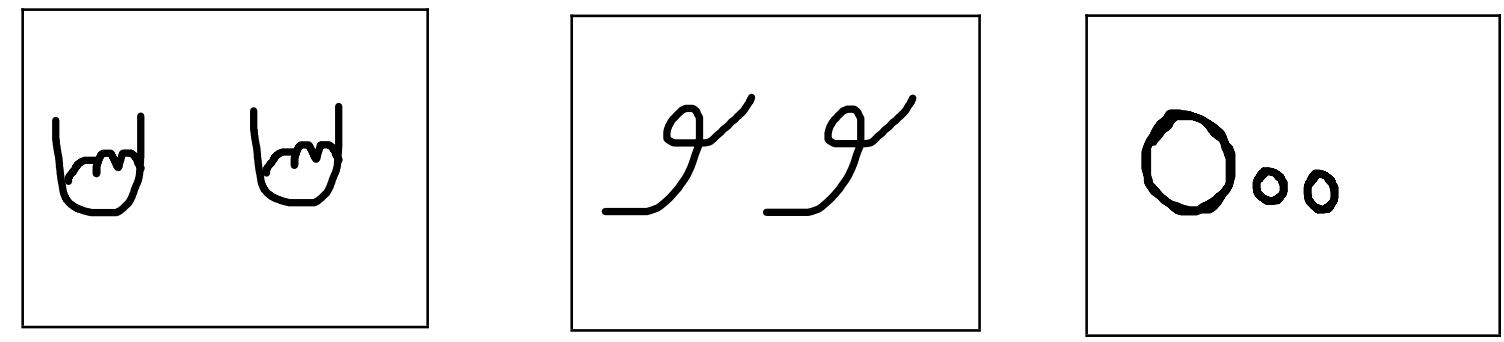

Figure 1. Pictures designed by students

Creativity is basically what happens within a person's experience ${ }^{[4]}$. Therefore, in order to cultivate students' creativity, it is important to pay attention to their emotional experience, aesthetic experience, activity experience, and so on. The use of information technology allows students to participate in classroom activities, which would enrich their experience and feelings, and eventually cultivate their creativity.

\subsection{Exercising students' reverse thinking and mobilizing students' learning enthusiasm}

The core of creative thinking lies in the uniqueness and advantage of thinking. In the teaching process, teachers are accustomed to using conventional teaching methods to help students master music theory from textbooks, while neglecting practical skills. Through learning, students would have acquired certain skills, such as music appreciation, singing, music analysis, performance, etc. Teachers should break students' existing cognition and encourage students to actively participate in different music activities. While teaching, teachers should ask questions without giving a fixed scope to encourage students to look for the answers outside their existing cognition and think about the answers from different perspectives. The answers can be common or elusive as the true aim is to fully mobilize students' enthusiasm by using reverse thinking to stimulate their creative thinking through the process of searching for answers. For example, in regard to the "Dance of the Youth," teachers can play three different speeds: slow, moderate, and fast. Through the comparison of the speed, the students are prompted to think about the speed that is suitable for the music. This way of reverse thinking makes students contemplate about the role of speed in the style of the music. Through such activities, students' reverse thinking and creative thinking skills can be better cultivated.

\section{Conclusion}

In music classes, good teaching is the result of teachers' professional quality. The integration of information technology creates more possibilities for better teaching. More emphasis should be on cultivating students' creativity and on the innovation of the teaching model, so that students' creative thinking can be fully developed. If teachers desire to uncover students' inner potential, they need to improve students' comprehensive quality.

Louis Leon Thurstone once said, "If a thinker seeks understanding at the end of an instant, and the solution implies something new to the thinker, then the behavior is creative ${ }^{[5]}$." Therefore, in the new era, educators should design a good learning activity for students in the teaching link, create a teaching situation, and encourage students to actively participate in the classroom through association. Teachers should follow the trend and introduce information technology into music classrooms to stimulate students' interest in learning. It is also necessary to use information technology to create interesting music lessons, stimulate students' creative thinking, and ensure that students are the "masters" in classrooms while being actively involved in music activities. 


\section{Disclosure statement}

The authors declare that there is no conflict of interest.

\section{References}

[1] The Ministry of Education of the People's Republic of China, 2011, The Music Curriculum Standards for Compulsory Education (2011 Edition), Beijing Normal University Press, 4.

[2] Liu Y, 2013, How to Cultivate Students' Creative Thinking in Music Teaching, Hunan Normal University.

[3] The Ministry of Education of the People's Republic of China, 2011, The Music Curriculum Standards for Compulsory Education (2011 Edition), Beijing Normal University Press, 21.

[4] Reamer B, 2003, A Philosophy of Music Education - Advancing the Vision (3rd Edition), People's Music Publishing House, 172.

[5] Reamer B, 2003, A Philosophy of Music Education - Advancing the Vision (3rd Edition), People's Music Publishing House, 167.

Publisher's note

Bio-Byword Scientific Publishing remains neutral with regard to jurisdictional claims in published maps and institutional affiliations. 